\title{
Fibrinogen Beta-Chain -C148T Polymorphism is Associated with Increased Fibrinogen, C-Reactive Protein, and Interleukin-6 in Patients Undergoing Coronary Artery Bypass Grafting
}

\author{
Ewa Wypasek, ${ }^{1,2,3}$ Ewa Stepien,,${ }^{1,2}$ Malgorzata Kot, ${ }^{1}$ Dariusz Plicner, ${ }^{1,2}$ Boguslaw Kapelak, \\ Jerzy Sadowski, ${ }^{1,2}$ and Anetta Undas ${ }^{1,2}$
}

\begin{abstract}
The fibrinogen beta-chain (FGB) -C148T polymorphism is linked with plasma fibrinogen concentration in the general population. We examined whether the $-\mathrm{C} 148 \mathrm{~T}$ polymorphism is associated with pre- and early postoperative levels of fibrinogen, C-reactive protein (CRP), and interleukin-6 (IL-6) in 243 consecutive patients undergoing coronary artery bypass grafting (CABG) surgery. Plasma inflammatory markers were measured prior to and 5-7 days after surgery. The -C148T polymorphism was analyzed with the restriction fragment-length polymorphism method. The genotype distribution was as follows: CC -142 (58\%), CT -85 (35\%), and TT -16 (7\%). Carriers of the $-148 \mathrm{~T}$ allele had higher preoperative plasma fibrinogen $(4.42 \pm 0.14 v \mathrm{~s} .4 .07 \pm 0.11 \mathrm{mg} / \mathrm{L}, p=0.04)$ and CRP levels $(7.49 \pm 1.2 v s .4 .26 \pm 1.0 \mathrm{mg} / \mathrm{L}, p=0.04)$ compared with non-carriers; 5 to 7 days after CABG, patients carrying $-148 \mathrm{~T}$ allele had increased CRP $(70.4 \pm 5.0$ vs. $51.6 \pm 4.25 \mathrm{mg} / \mathrm{L}$, $p=0.005)$ and IL-6 levels $(22.34 \pm 2.64 v s .15 .53 \pm 2.28 \mathrm{pg} / \mathrm{L}, p=0.05)$, but not fibrinogen, compared with the remaining subjects. In-hospital nonfatal stroke occurred more frequently in -148T allele carriers ( $4 \%$ vs. $0 \%, p=0.02)$. No genotype-associated differences were found in the occurrence of postoperative myocardial infarction and death. Presence of the $-148 \mathrm{~T}$ allele has also been associated with longer intensive care stay and intubation time $(p=0.01)$. Multivariate analysis identified the CT+TT genotype as an independent predictor of pre- and postoperative CRP levels. The results indicate that the presence of the -148T FGB allele determines higher pre- and postoperative levels of inflammatory markers, which might be associated with in-hospital clinical outcomes.
\end{abstract}

KEY WORDS: CABG; -C148T FGB polymorphism; inflammation; CRP; fibrinogen; IL-6.

\section{INTRODUCTION}

Fibrinogen is encoded by three separate genes located in a $50-\mathrm{Kb}$ cluster on the long arm of chromosome 4 , which encode for the $\alpha, \beta$, and $\gamma$ chains [1]. The rate limiting step in fibrinogen formation is the synthesis of the $\beta$-polypeptide chain regulated by a

\footnotetext{
${ }^{1}$ Institute of Cardiology, Jagiellonian University Medical College, 80 Pradnicka St., 31-202, Cracow, Poland

${ }^{2}$ John Paul II Hospital, Cracow, Poland

${ }^{3}$ To whom correspondence should be addressed at Institute of Cardiology, Jagiellonian University Medical College, 80 Pradnicka St., 31-202, Cracow, Poland. E-mail: ewa.wypasek@uj.edu.pl
}

$\beta$-fibrinogen promoter [2]. One of the polymorphisms identified within this region is $-\mathrm{C} 148 \mathrm{~T}$ mutation located close to an interleukin-6-response element affecting fibrinogen gene expression, mainly in response to the acute-phase reaction [3]. This polymorphism is in complete allelic association with -G455A in white population [4]. Several studies have shown that a -C148T polymorphism is associated with increased plasma fibrinogen levels in men and women in the general population [5-7]. Fibrinogen conversion to fibrin is the final step in the blood coagulation. Moreover, fibrinogen acts as a bridging molecule for many types of cell-cell adhesion events critical in atherogenesis [8]. Fibrinogen synthesis is upregulated primarily by interleukin-6 (IL-6) which controls the hepatic production 
of C-reactive protein (CRP). The studies included both genders, European and American cohorts, both middle-aged and elderly patients showed that in addition to predicting cardiovascular death and myocardial infarction, CRP is also a robust predictor of stroke [9].

Coronary artery bypass grafting $(\mathrm{CABG})$ procedure is a strong inflammatory stimulus that causes a substantial rise in circulating CRP, fibrinogen, and IL-6 levels [10-12]. Patients having CRP value greater or equal to $3.3 \mathrm{mg} / \mathrm{l}$ preoperatively suffered from myocardial damage, heart failure, or stroke during first 30 days after CABG [13]. High-plasma IL-6 concentrations were in turn significantly associated with postoperative fever [10], atrial fibrillation [14], prolonged endotracheal intubation time, and duration of intensive care $[15,16]$. Inflammatory response after CABG might be modified by polymorphisms in pro-inflammatory genes. Brull et al. showed that high CRP level was significantly and independently associated with + C1444T CRP gene polymorphism at $72 \mathrm{~h}$ after CABG surgery [11]. Similarly, the G/A transitions within the promoter region of the TNF- $\alpha$ gene and the first intron of the TNF- $\beta$ gene were associated with elevated levels of TNF- $\alpha$ up to $48 \mathrm{~h}$ after surgery [17]; 5 to 7 days after $C A B G$, significant increase of CRP and IL-6 levels was determined by IL-6 -174G/C polymorphism: patients carrying $-174 \mathrm{C}$ allele had CRP and IL-6 levels higher than those with -174GG genotype [15].

The aim of our study was to assess whether -C148T FGB polymorphism is associated with acute-phase proteins and adverse postoperative cardiovascular events in CABG patients.

\section{METHODS}

\section{Patients}

We recruited 243 consecutive white patients with stable angina admitted to the Department of Cardiovascular Surgery and Transplantation, Institute of Cardiology, Jagiellonian University School of Medicine for elective isolated CABG surgery between January and September 2006. Inclusion criteria were as follows: significant stenosis in the left main coronary artery $(>50 \%)$ or major epicardial arteries $(>70 \%)$ determined by coronary angiography in patients who were not scheduled for percutaneous coronary intervention. The exclusion criteria were other surgical procedures on the same day, emergency operation, signs, or symptoms of acute infections, treatment with vitamin $\mathrm{K}$ antagonists, heparins, or thienopyridines, a history of venous thromboembolism, a previous acute coronary syndrome within less than 3 months prior to surgery, serious concomitant diseases such as cancer, autoimmune disorders, end-stage renal insufficiency, liver injury, presence of extensive dental disease. Patients with preoperative CRP $>10 \mathrm{mg} / \mathrm{l}$ were excluded from the final analysis because there was a high probability of chronic inflammatory state of unknown origin.

In case of an elevated fasting glucose a confirmatory test (a 75-g oral glucose tolerance test) was made to screen for diabetes. Arterial hypertension was diagnosed if diastolic blood pressure exceeded $90 \mathrm{mmHg}$ and/or systolic pressure was $>140 \mathrm{mmHg}$ at least two times or the use of antihypertensive drugs at a positive history of this disease. Ischemic stroke was diagnosed according to the WHO criteria [18]. The diagnosis of perioperative myocardial infarction (PMI) was based on the criteria published in 2004 [19]. The University Ethical Committee approved the study, and participants provided informed consent.

\section{Laboratory Investigations}

Blood samples were drawn from an anticubital vein with minimal stasis after an overnight fast. Lipid profiles, glucose, and creatinine were assayed by routine laboratory techniques. Fibrinogen was determined using the Clauss method [20]. High-sensitivity CRP was measured by an immuno-turbidimetric assay (Dade Behring, Marburg, Germany). A commercially available immunoenzymatic assay was used to determine serum IL-6 levels (R\&D System Inc., Minneapolis, USA). The minimal detectable IL- 6 concentration was $0.03 \mathrm{pg} / \mathrm{ml}$. All measurements were performed by technicians blinded to the origin of the samples. Intra- and inter-assay coefficients of variation were $<7 \%$.

\section{DNA Extraction and Genotyping}

DNA was extracted from whole blood or a buffy coat according to the manufacturer's protocol using the GenElute $^{\mathrm{TM}}$ Blood Genomic DNA Kit (Sigma-Aldrich) and stored at $-20^{\circ} \mathrm{C}$ until analysis. The polymorphism of the fibrinogen beta-chain gene-C148T was genotyped by PCR and restriction fragment-length polymorphism method using primer pairs 5' CCTAACTTCCCAT CATTTTGTCCAATTAA 3'/5' TGTCGTTGACA 
CCTTGGGACTTAAC TAG-3' and Hind III digestion (recognition sequence-AAGCTT) resulted in fragments of 97 and $265 \mathrm{bp}$ for the $\mathrm{C}$ allele $(-148 \mathrm{C})$ or $362 \mathrm{bp}$ for the T allele (-148T) [21].

\section{Statistical Analysis}

Data are given as means \pm SD unless otherwise stated. The Kolmogorov-Smirnov test was used to assess conformity with a normal distribution. Allele frequencies were estimated by gene counting. The $\chi^{2}$ test was used to compare the observed numbers of each genotype with those expected for a population in Hardy-Weinberg equilibrium. The variables were compared with Student's $t$ test and analysis of variance. Correlations were assessed by the Spearman test. To identify independent factors of CRP levels, a stepwise multivariate linear regression analysis was used in which a $p$ value less than 0.05 in a simple regression analysis was served as the criterion for entry into the model. Variables showing established cardiovascular risk factors were also included. The logistic regression analysis was employed to estimate the odds ratio and $95 \%$ coefficient intervals (CIs) as a relative risk of PMI with the prevalence of a mutant allele and the levels of acute phase proteins. A value of $p<0.05$ was considered statistically significant. Analysis was performed by use of Statistica 7.1 PL package (StatSoft, Inc. 2005).

\section{RESULTS}

\section{Patient Characteristics}

Among the 243 patients who underwent CABG surgery, $185(76 \%)$ were male. A mean age of the patients was $64.6 \pm 8.2$ (range from 42 to 82 ) years. A mean body mass index (BMI) was $28 \pm 4.0 \mathrm{~kg} / \mathrm{m}^{2}$. Two hundred twenty-five patients $(92 \%)$ were treated with statins, 218 (90\%) with beta-blockers, 211 (87\%) with angiotensin-converting enzyme inhibitors, 23 (9\%) with acetylsalicylic acid. Sixty-seven subjects (27.6\%) were current smokers. Arterial hypertension was diagnosed in $207(85 \%)$ patients, previous myocardial infarction in $197(81 \%)$ patients, diabetes in 70 (29\%), chronic

Table 1. Baseline Demographic and Clinical Characteristic of Patients with Regard to -C148T FGB Polymorphism

\begin{tabular}{|c|c|c|c|}
\hline Demographic and clinical data & $\mathrm{CC}(n=142)$ & $\mathrm{CT}+\mathrm{TT}(n=101)$ & $p$ Value \\
\hline Age, years & $64.34 \pm 0.69$ & $65.27 \pm 0.82$ & 0.39 \\
\hline Male gender, $n(\%)$ & $109(77)$ & $76(75)$ & 0.68 \\
\hline BMI, $\mathrm{kg} / \mathrm{m}^{2}$ & $27.85 \pm 0.34$ & $28.17 \pm 0.4$ & 0.55 \\
\hline Current smokers, $n(\%)$ & $38(27)$ & $29(29)$ & 0.78 \\
\hline Hypertension, $n(\%)$ & $122(86)$ & $85(84)$ & 0.68 \\
\hline Diabetes, $n(\%)$ & $37(26)$ & $33(33)$ & 0.3 \\
\hline COPD, $n(\%)$ & $10(7)$ & $3(3)$ & 0.17 \\
\hline Previous MI, $n(\%)$ & $114(80)$ & $83(82)$ & 0.71 \\
\hline \multicolumn{4}{|l|}{ Medications } \\
\hline ASA, $n(\%)$ & $21(15)$ & $2(2)$ & 0.25 \\
\hline Statins, $n(\%)$ & $129(91)$ & $96(95)$ & 0.28 \\
\hline$\beta$-blockers, $n(\%)$ & $131(92)$ & $87(86)$ & 0.12 \\
\hline ACE inhibitors, $n(\%)$ & $124(87)$ & $87(86)$ & 0.89 \\
\hline \multicolumn{4}{|l|}{ Laboratory parameters } \\
\hline Creatinine, $\mu \mathrm{mol} / \mathrm{L}(n=144)$ & $86.56 \pm 2.36$ & $77.60 \pm 2.88$ & 0.02 \\
\hline $\mathrm{TC}, \mathrm{mmol} / \mathrm{L}$ & $4.69 \pm 0.09$ & $4.59 \pm 0.11$ & 0.45 \\
\hline HDL-C, mmol/L & $1.24 \pm 0.02$ & $1.2 \pm 0.03$ & 0.35 \\
\hline $\mathrm{LDL}-\mathrm{C}, \mathrm{mmol} / \mathrm{L}$ & $2.96 \pm 0.08$ & $2.90 \pm 0.09$ & 0.46 \\
\hline $\mathrm{TG}, \mathrm{mmol} / \mathrm{L}$ & $1.61 \pm 0.09$ & $1.85 \pm 0.1$ & 0.07 \\
\hline CRP, mg/L & $4.26 \pm 1.01$ & $7.49 \pm 1.2$ & 0.04 \\
\hline $\mathrm{Fbg}, \mathrm{g} / \mathrm{L}$ & $4.07 \pm 0.11$ & $4.42 \pm 0.14$ & 0.04 \\
\hline
\end{tabular}

Values are given as mean $\pm \mathrm{SD}$ or number (percentage)

$A C E$ angiotensin-converting enzyme, $A S A$ acetylsalicylic acid, $B M I$ body mass index, $M I$ myocardial infarction, $C R P$ C-reactive protein, $C O P D$ chronic obstructive pulmonary disease, $F b g$ fibrinogen, $H D L-C$ high-density lipoprotein cholesterol, $L D L-C$ low-density lipoprotein cholesterol, $T C$ total cholesterol, $T G$ triglycerides 
Table 2. Procedure-Related Data in Relation to -C148T FGB Polymorphism

\begin{tabular}{lccc}
\hline Operative details & $\mathrm{CC}(n=142)$ & $\mathrm{CT}+\mathrm{TT}(n=101)$ & $p$ Value \\
\hline Euroscore, per patient & $2.66 \pm 0.14$ & $2.78 \pm 0.17$ & 0.6 \\
Drainage, mL & $744.96 \pm 35$ & $784.12 \pm 42.96$ & 0.5 \\
Number of grafts, per patient & $2.61 \pm 0.06$ & $2.75 \pm 0.07$ & 0.1 \\
Aortic cross clamp, min & $40.38 \pm 1.21$ & $41.76 \pm 1.47$ & 0.5 \\
Extracorporeal circulation, min & $86.4 \pm 2.69$ & $91.75 \pm 3.27$ & 0.2 \\
Intubation time, days & $1.26 \pm 0.24$ & $2.2 \pm 0.29$ & 0.01 \\
Intensive care stay, days & $2.14 \pm 0.35$ & $3.63 \pm 0.41$ & 0.007 \\
\hline
\end{tabular}

obstructive pulmonary disease (COPD) in $13(5 \%)$. The mean Euroscore was 5.2 \pm 1.55 .

\section{-C148T Polymorphism}

We identified 142 subjects with -148C genotype, 85 heterozygous and 16 patients homozygous for the $-148 \mathrm{~T}$ allele. Genotype distribution did not differ significantly from that predicted by the Hardy-Weinberg equilibrium law $\left(\chi^{2}=0.45\right)$. The $\mathrm{T}$ allele frequency was $24.0 \%$, a finding consistent with studies in other European and Caucasian populations of the -C148T (or -G455A) polymorphisms [21]. Both genotype groups did not differ with regard to cardiovascular risk factors and medications (Table 1). There were no inter-group differences in glucose and lipid profile, but fibrinogen and CRP levels were higher in $\mathrm{T}$ allele carriers than in CC patients $(4.42 \pm 0.14$ vs. $4.07 \pm 0.11 \mathrm{~g} / \mathrm{L}, p=0.04$; $7.49 \pm 1.2$ vs. $4.26 \pm 1.01 \mathrm{mg} / \mathrm{L}, p=0.04$, respectively). Higher serum creatinine levels were observed in CC patients (Table 1). Creatinine concentrations did not correlate with inflammatory markers and did not predict clinical outcomes in our group.

As expected, there was a positive correlation between baseline CRP and IL-6 concentrations $(r=0.5, p<0.0001)$. The basal fibrinogen levels were positively correlated with CRP $(r=0.6, p<0.0001)$ and IL-6 $(r=0.4 ; p<0.0001)$ levels.

\section{CABG and Perioperative Clinical Outcomes}

The surgery was performed by four cardiac surgeons using a standard cardiopulmonary bypass technique. The number of grafts per patient was $2.65 \pm$ 0.70 . The mean aortic cross clamp time was $40.9 \pm 14.1$ (range 12-100) min. The mean duration of extracorporeal circulation was $89.6 \pm 33.8$ (range 40-270) min. Intensive care stay was $2.8 \pm 4.2$ days. There were no associations between -C148T FGB polymorphism and any procedurerelated variables; however, intubation time and the length of intensive care unit stay were prolonged in $\mathrm{T}$ allele carriers (Table 2).

During hospital stay, there were 22 major adverse cardiovascular events, including five cardiovascular deaths, 13 myocardial infarctions, and four ischemic strokes. The logistic regression analysis showed that basal fibrinogen levels in patients in the highest quartile was associated with a 8.8 -fold increased risk of perioperative $\mathrm{MI}$ in $\mathrm{CABG}$ patients $(95 \% \mathrm{CI}=2.01$ to $40.46, P=0.004)$. The frequency of adverse cardiovascular events, cardiovascular deaths, and PMI was similar in patients with $-148 \mathrm{~T}$ allele and those with CC genotype. Interestingly, four nonfatal ischemic strokes were observed among -148T allele carriers during postoperative period, while no such episode occurred in the $\mathrm{CC}$ patients (Table 3). Patients with stroke had higher CRP levels compared to those without this complication $(19.9 \pm 6.0 \mathrm{vs}$. $5.4 \pm 0.8 \mathrm{mg} / \mathrm{L}, p=0.005)$.

\section{The Inflammatory Response after CABG}

CRP, fibrinogen, and IL-6 levels measured postoperatively were available in only 124 patients. We initially recruited 243 patients, but 119 subjects were excluded from the postoperative analysis due to incomplete clinical and laboratory data $(n=19)$, transfer to other wards $(n=95)$, or patient refusal $(n=5)$.

Five to seven days after $\mathrm{CABG}$, mean CRP increased more than 10-fold from $4.3 \pm 0.1$ to $62.5 \pm$ $4.2 \mathrm{mg} / \mathrm{L}(p<0.0001)$. A mean IL-6 rose 6-fold from $3.1 \pm 0.23$ preoperatively to $20.05 \pm 2.4 \mathrm{pg} / \mathrm{mL}$ after surgery $(p<0.0001)$. The magnitude of a postoperative

Table 3. Major Adverse Cardiovascular Events During Perioperative Period in Relation to -C148T FGB Polymorphism

\begin{tabular}{lccc}
\hline Cardiovascular events & CC $n(\%)$ & CT+TT $n(\%)$ & $p$ Value \\
\hline Death & $1(0.7)$ & $4(4)$ & 0.2 \\
Non-fatal MI & $8(6)$ & $5(5)$ & 0.8 \\
Non-fatal stroke & $0(0)$ & $4(4)$ & 0.02 \\
\hline
\end{tabular}



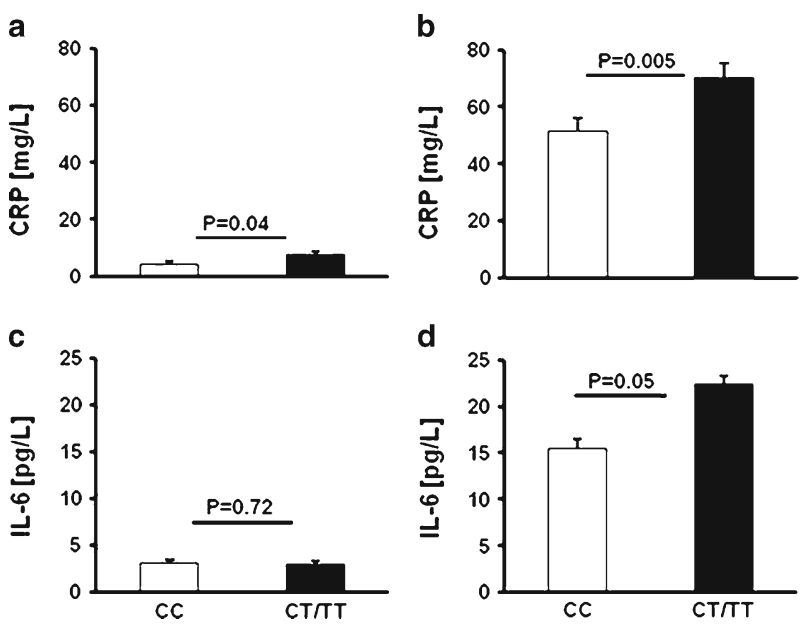

Fig. 1. Baseline (a, c) and postoperative (b, d) CRP and IL-6 levels determined in $-148 \mathrm{CC}$ and $-148 \mathrm{~T}$ carriers. Values are given as mean \pm standard deviation.

increase in CRP levels was associated with postoperative fibrinogen $(r=0.4, p<0.0005)$ and IL-6 levels $(r=0.53, p<0.0001)$, intubation time $(r=0.24$, $p=0.01)$, and duration of intensive care $(r=0.25, p=0.01)$.

The IL-6 rise following surgery was positively correlated with postoperative fibrinogen $(r=0.3, p=0.02)$ and CRP levels $(r=0.5, p<0.0001)$.

Five to seven days after surgery carriers of the $-148 \mathrm{~T}$ allele had 36\% higher CRP and 44\% higher IL-6 levels than those having $-148 \mathrm{CC}$ genotype (70.4 $\pm 5.0 \mathrm{vs}$. $51.6 \pm 4.25 \mathrm{mg} / \mathrm{L}, p=0.005$ and $22.34 \pm 2.64$ vs. $15.53 \pm$ $2.28 \mathrm{pg} / \mathrm{ml}, p=0.05$, respectively; Fig. 1). Multivariate regression analysis including sex, age, BMI, smoking, COPD, hypertension, diabetes, and CT+TT genotype identified COPD and CT + TT genotype as the independent predictors of basal CRP levels $\left(R^{2}=0.1, p=0.02\right)$ in coronary artery disease (CAD) patients (Table 5); 5 to 7 days following surgery CT+TT genotype was the only independent predictor of postoperative CRP levels $\left(R^{2}=0.1, p=0.03\right.$, Table 4$)$.

\section{DISCUSSION}

This study shows that beta-fibrinogen gene -C148T polymorphism modulates concentrations of the acute phase proteins in patients with advanced CAD. Baseline plasma fibrinogen and CRP levels as well as CRP and IL-6 levels measured 5-7 days following CABG were significantly higher in $-148 \mathrm{~T}$ allele carriers. It should be highlighted that the influence of -C148T polymorphism on inflammatory markers is potent enough to be detected in the early postoperative period in patients undergoing $\mathrm{CABG}$. Postoperative fibrinogen appears to be subjected to other strong modulators and the effect of $-148 \mathrm{~T}$ allele on fibrinogen is abolished after surgery.

The acute-phase proteins may be involved in the occurrence of perioperatve adverse events in CABG patients. Indeed, patients in the highest quartile of fibrinogen levels had increased risk of PMI (odds ratio 8.8). Perioperative MI worsens prognosis in patients after CABG surgery, both during short- and long-term follow-up [22, 23]. Patients with PMI were more likely to have a cardiac event within 30 months after operation [24]. Furthermore, 3-year survival averaged $85 \%$ of patients with PMI compared with $95 \%$ of patients without such a cardiac event at operation [25]. Moreover, we showed that CRP levels might be also affected by $-\mathrm{C} 148 \mathrm{~T}$ FBG polymorphism. There is evidence that preoperative elevated CRP levels are associated with a significantly increased risk of postoperative death [26], heart failure [13], low cardiac output syndrome [27], recurrent ischemia [28], or stroke

Table 4. Multiple Regression Analysis for the Risk Factors and Basal and Postoperative CRP Levels

\begin{tabular}{|c|c|c|c|c|c|c|}
\hline & \multicolumn{3}{|c|}{$\mathrm{CRP} R^{2}=0.11, p=0.02$} & \multicolumn{3}{|c|}{ CRP after CABG $R^{2}=0.10, p=0.03$} \\
\hline & Beta & SE & $p$ & Beta & SE & $p$ \\
\hline Sex & 0.09 & 0.07 & 0.17 & -0.10 & 0.08 & 0.19 \\
\hline Age & 0.12 & 0.07 & 0.09 & 0.001 & 0.08 & 0.99 \\
\hline BMI & -0.03 & 0.07 & 0.70 & 0.12 & 0.08 & 0.15 \\
\hline Smoking & -0.02 & 0.07 & 0.80 & 0.08 & 0.08 & 0.30 \\
\hline Hypertension & 0.04 & 0.07 & 0.58 & 0.09 & 0.08 & 0.23 \\
\hline Diabetes & -0.01 & 0.07 & 0.16 & -0.05 & 0.08 & 0.57 \\
\hline COPD & 0.17 & 0.07 & 0.01 & 0.21 & 0.07 & 0.30 \\
\hline -C148T FGB polymorphism & 0.15 & 0.07 & 0.03 & 0.15 & 0.07 & 0.05 \\
\hline
\end{tabular}


[13] during follow-up. The inflammatory pathways may be important mechanistic factors in either initiating or otherwise modulating stroke after cardiac surgery $[9,29]$. We extended these findings by showing that the presence of the $\mathrm{T}$ allele might affect in-hospital adverse outcomes following CABG. In the current study, the incidence of perioperative nonfatal ischemic stroke was observed in four of $-148 \mathrm{~T}$ allele carriers who had significantly higher CRP levels than patients without stroke. It might be speculated that the beta-fibrinogen gene -C148T polymorphism contributes to the etiology of perioperative stroke by modulating the fibrinogen and CRP expression. Perioperative strokes result in a prolonged hospital stay, increased rates of disability, and discharge to long-term care facilities [30].

We found that CT+TT genotype is an independent predictor of high postoperative CRP levels in CABG patients. Inflammatory gene polymorphism associated with variation in concentrations of inflammatory markers has additional impact on severity of inflammation after surgery. This enhanced inflammatory reaction might be connected with different cardiovascular events developed in the postoperative period [31, 32]. In our study, the prolonged endotracheal intubation time and the duration of intensive care were associated with the T allele presence linked with the considerable increase of in-hospital stay. Carrying of the $-148 \mathrm{~T}$ allele has also been associated with increased postoperative IL-6 levels in CABG patients.

It is known that IL-6 exert its inflammatory effects by upregulating fibrinogen expression and the $-\mathrm{C} 148 \mathrm{~T}$ polymorphism is a major regulator of this process [33]. Moreover, the -C148T polymorphism affects plasma fibrinogen levels only in subgroups with higher IL-6 and CRP levels such as healthy smokers [34]. It seems that the -C148T polymorphism may affect not only fibrinogen gene expression but also other pro-inflammatory proteins like CRP at transcriptional level. Further studies will, therefore, be necessary to clarify this association.

This study has limitations. First, patients were not followed after hospital discharge. A 1-year or longer follow-up might provide new insights into the genetic background of postoperative inflammatory response and its association with long-term prognosis following CABG. Secondly, the sample size was limited, and the number of cardiovascular events recorded following surgery during hospital stay is rather low. Analysis of subgroups could be just underpowered to show significant differences. Third, CRP, fibrinogen, and IL-6 levels measured 5-7 days after CABG were available not in all patients. Therefore, we cannot exclude that subjects with severe comorbidities were not included in the postoperative analysis. Finally, the data cannot be extrapolated to emergency or urgent $\mathrm{CABG}$, in which acute phase reaction is usually more potent.

In conclusion, we found that -C148T FGB polymorphism was an independent predictor of pre- and early postoperative CRP levels in CABG patients. Preoperative fibrinogen levels and postoperative IL-6 levels were higher in $\mathrm{T}$ allele carriers. Polymorphism in pro-inflammatory genes may modulate the severity of inflammation and be associated with clinical outcomes in the early postoperative period in patients undergoing elective CABG.

\section{ACKNOWLEDGEMENTS}

This work was supported by Jagiellonian University School of Medicine Grant K/ZDS/000509 (BK).

Open Access. This article is distributed under the terms of the Creative Commons Attribution Noncommercial License which permits any noncommercial use, distribution, and reproduction in any medium, provided the original author(s) and source are credited.

\section{REFERENCES}

1. Kant, J.A., A.J. Fornace Jr., D. Saxe, M.I. Simon, O.W. McBride, and G.R. Crabtree. 1985. Evolution and organization of the fibrinogen locus on chromosome 4:Gene duplication accompanied by transposition and inversion. Proceedings of the National Academy of Sciences of the United States of America 82: 2344-2348.

2. Roy, S.N., G. Mukhopadhyay, and C.M. Redman. 1990. Regulation of fibrinogen assembly. Transfection of Hep G2 cells with B beta cDNA specifically enhances synthesis of the three component chains of fibrinogen. The Journal of Biological Chemistry 265: 6389-6393.

3. Thomas, A., H. Lamlum, S. Humphries, and F. Green. 1994. Linkage disequilibrium across the fibrinogen locus as shown by five genetic polymorphisms, G/A-455 (Hae III), C/T-148(Hind III/Alu I), T/G11689(Ava II), and Bcl I (b-fibrinogen) and Taq I (a-fibrinogen) and their detection by PCR. Human Mutation 3: 79-81.

4. Cook, D.G., F.P. Cappuccio, R.W. Atkinson, P.D. Wicks, A. Chitolie, E.R. Nakandakare, G.A. Sagnella, and S.E. Humphries. 2001. Ethnic differences in fibrinogen levels: the role of environmental factors and the beta-fibrinogen gene. American Journal of Epidemiology 153: 799-806.

5. Papageorgiou, N., D. Tousoulis, G. Siasos, and C. Stefanadis. 2010. Is fibrinogen a marker of inflammation in coronary artery disease? Hellenic Journal of Cardiology 51: 1-9.

6. van 't Hooft, F.M., S.J. von Bahr, A. Silveira, A. Iliadou, P. Eriksson, and A. Hamsten. 1999. Two common, functional poly- 
morphisms in the promoter region of the beta-fibrinogen gene contribute to regulation of plasma fibrinogen concentration. Arteriosclerosis, Thrombosis, and Vascular Biology 12: 3063-3070.

7. Tybjaerg-Hansen, A., B. Agerholm-Larsen, S.E. Humphries, S. Abildgaard, P. Schnohr, and B.G. Nordestgaard. 1997. A common mutation (G-455-A) in the beta-fibrinogen promoter is an independent predictor of plasma fibrinogen, but not of ischemic heart disease. A study of 9,127 individuals based on the Copenhagen City Heart Study. The Journal of Clinical Investigation 99: 3034-3039.

8. Mosesson, M.W., K.R. Siebenlist, and D.A. Meh. 2001. The structure and biological features of fibrinogen and fibrin. Annals of the New York Academy of Sciences 936: 11-30.

9. Rost, N.S., P.A. Wolf, C.S. Kase, M. Kelly-Hayes, H. Silbershatz, J. M. Massaro, R.B. D'Agostino, C. Franzblau, and P.W. Wilson. 2001. Plasma concentration of C-reactive protein and risk of ischemic stroke and transient ischemic attack: the Framingham study. Stroke 32: 2575-2579.

10. Mitchell, J.D., H.P. Grocott, B. Phillips-Bute, J.P. Mathew, M.F. Newman, and S. Bar-Yosef. 2007. Cytokine secretion after cardiac surgery and its relationship to postoperative fever. Cytokine 38: 37-42.

11. Brull, D.J., N. Serrano, F. Zito, L. Jones, H.E. Montgomery, A. Rumley, P. Sharma, G.D. Lowe, M.J. World, S.E. Humphries, and A.D. Hingorani. 2003. Human CRP gene polymorphism influences CRP levels: implications for the prediction and pathogenesis of coronary heart disease. Arteriosclerosis, Thrombosis, and Vascular Biology 23: 2063-2069.

12. Cotton, J.M., K.E. Webb, A. Mathur, J.F. Martin, and S.E. Humphries. 2000. Impact of the $-455 \mathrm{G}>\mathrm{A}$ promoter polymorphism in the $\mathrm{B}$ fibrinogen gene on stimulated fibrinogen production following bypass surgery. Thrombosis and Haemostasis 84: 926-927.

13. Balciunas, M., L. Bagdonaite, R. Samalavicius, L. Griskevicius, and A. Vuylsteke. 2009. Pre-operative high sensitive C-reactive protein predicts cardiovascular events after coronary artery bypass grafting surgery: a prospective observational study. Annals of Cardiac Anaesthesia 12: 127-132.

14. Gaudino, M., F. Andreotti, R. Zamparelli, A. Di Castelnuovo, G. Nasso, F. Burzotta, L. Iacoviello, M.B. Donati, R. Schiavello, A. Maseri, and G. Possati. 2003. The $2174 \mathrm{G} / \mathrm{C}$ interleukin-6 polymorphism influences postoperative interleukin-6 levels and postoperative atrial fibrillation. Is atrial fibrillation an inflammatory complication? Circulation 108: 195-199.

15. Wypasek, E., A. Undas, M. Sniezek-Maciejewska, B. Kapelak, D. Plicner, E. Stepien, and J. Sadowski. 2010. The increased plasma C-reactive protein and interleukin-6 levels in patients undergoing coronary artery bypass grafting surgery are associated with the interleukin-6-174G $>\mathrm{C}$ gene polymorphism. Annals of Clinical Biochemistry 47: 343-349.

16. Puyo, C.A., S.M. Tricomi, and T.E. Dahms. 2008. Early biochemical markers of inflammation in a swine model of endotracheal intubation. Anesthesiology 109: 88-94.

17. Yende, S., M. Quasney, Q. Zhang, K. Frederick, L. Kessler, and R. G. Wunderink. 2002. Impact of cytokine gene polymorphisms on outcomes of coronary artery bypass graft surgery. Chest 121: $86 \mathrm{~S}$.

18. Hatano, S. 1976. Experience from a multicentre stroke register: a preliminary report. Bulletin of the World Health Organization 54: 541-553.

19. Eagle, K.A., R.A. Guyton, R. Davidoff, F.H. Edwards, G.A. Ewy, T.J. Gardner, J.C. Hart, H.C. Herrmann, L.D. Hillis, A.M. Jr Hutter, B.W. Lytle, R.A. Marlow, W.C. Nugent, T.A. Orszulak, and for the American College of Cardiology/American Heart Association Task Force on Practice Guidelines Committee to Update the 1999 Guidelines for Coronary Artery Bypass Graft Surgery, American Society for Thoracic Surgery, and Society of Thoracic Surgeons. 2004. ACC/AHA 2004 guideline update for coronary artery bypass graft surgery: summary article: a report of the American College of Cardiology/American Heart
Association Task Force on Practice Guidelines. Journal of the American College of Cardiology 44(1146-54): e213-e310.

20. Clauss, A. 1957. Gerinnungsphysiologische Schnellmethode zur Bestimmung des Fibrinogens. [Rapid physiological coagulation method in determination of fibrinogen.]. Acta Haematologica 17: 237-246.

21. Blake, G.J., C. Schmitz, K. Lindpaintner, and P.M. Ridker. 2001. Mutation in the promoter region of the beta-fibrinogen gene and the risk of future myocardial infarction, stroke and venous thrombosis. European Heart Journal 22: 2262-2266.

22. Steuer, J., L.G. Hörte, B. Lindahl, and E. Ståhle. 2002. Impact of perioperative myocardial injury on early and long-term outcome after coronary artery bypass grafting. European Heart Journal 23: 1219-1227.

23. Carrier, M., M. Pellerin, L.P. Perrault, B.C. Solymoss, and L.C. Pelletier. 2000. Troponin levels in patients with myocardial infarction after coronary artery bypass grafting. The Annals of Thoracic Surgery 69: 435-440.

24. Force, T., P. Hibberd, G. Weeks, A.J. Kemper, P. Bloomfield, D. Tow, M. Josa, S. Khuri, and A.F. Parisi. 1990. Perioperative myocardial infarction after coronary artery bypass surgery. Clinical significance and approach to risk stratification. Circulation 82: 903-912.

25. Chaitman, B.R., E.L. Alderman, L.T. Sheffield, T. Tong, L. Fisher, M.B. Mock, R.D. Weins, G.C. Kaiser, D. Roitman, R. Berger, B. Gersh, H. Schaff, M.G. Bourassa, and T. Killip. 1983. Use of survival analysis to determine the clinical significance of new Q waves after coronary bypass surgery. Circulation 67: 302-307.

26. Palmerini, T., A. Marzocchi, C. Marrozzini, L.B. Reggiani, C. Savini, G. Marinelli, R. Di Bartolomeo, and A. Branzi. 2007. Preoperative C-reactive protein levels predict 9-month mortality after coronary artery bypass grafting surgery for the treatment of left main coronary artery stenosis. European Journal of Cardiothoracic Surgery 31: 685-690.

27. Biancari, F., J. Lahtinen, S. Lepojärvi, P. Rainio, E. Salmela, R. Pokela, M. Lepojärvi, J. Satta, and T.S. Juvonen. 2003. Preoperative C-reactive protein and outcome after coronary artery bypass surgery. The Annals of Thoracic Surgery 76: 2007-2012.

28. Milazzo, D., L.M. Biasucci, N. Luciani, L. Martinelli, C. Canosa, R. Schiavello, A. Maseri, and G. Possati. 1999. Elevated levels of C-reactive protein before coronary artery bypass grafting predict recurrence of ischemic events. The American Journal of Cardiology 84: 459-461.

29. Grocott, H.P., W.D. White, R.W. Morris, M.V. Podgoreanu, J.P. Mathew, D.M. Nielsen, D.A. Schwinn, and M.F. Newman. 2005. Perioperative Genetics and Safety Outcomes Study (PEGASUS) Investigative Team. Genetic polymorphisms and the risk of stroke after cardiac surgery. Stroke 36: 1854-1858.

30. Selim, M. 2007. Perioperative stroke. The New England Journal of Medicine 356: 706-713.

31. Asimakopoulos, G. 2001. Systemic inflammation and cardiac surgery: an update. Perfusion 16: 353-360.

32. Ascione, R., C.T. Lloyd, M.J. Underwood, A.A. Lotto, A.A. Pitsis, and G.D. Angelini. 2000. Inflammatory response after coronary revascularization with or without cardiopulmonary bypass. The Annals of Thoracic Surgery 69: 1198-1204.

33. Verschuur, M., M. de Jong, L. Felida, M.P. de Maat, and H.L. Vos. 2005. A hepatocyte nuclear factor- 3 site in the fibrinogen beta promoter is important for interleukin 6-induced expression, and its activity is influenced by the adjacent $-148 \mathrm{C} / \mathrm{T}$ polymorphism. The Journal of Biological Chemistry 280: 16763-16771.

34. Gardemann, A., O. Schwartz, W. Haberbosch, N. Katz, T. Weiss, H. Tillmanns, F.W. Hehrlein, W. Waas, and A. Eberbach. 1997. Positive association of the beta fibrinogen $\mathrm{H} 1 / \mathrm{H} 2$ gene variation to basal fibrinogen levels and to the increase in fibrinogen concentration during acute phase reaction but not to coronary artery disease and myocardial infarction. Thrombosis and Haemostasis 77: 1120-1126. 